\title{
Avaliação microbiológica de presunto fatiado comercializado no município de Pau Brasil-BA
}

\author{
Microbiological evaluation of sliced ham sold \\ in the municipality of Pau Brazil-BA
}

Adenilson Soares Sena ${ }^{\text {I }}$ Marcel Vieira Santana ${ }^{\mathrm{I}}$ Gedeany Alves Nascimento Marcio Amorim Tolentino Lima ${ }^{1}$ Lucas Ribeiro Carvalho ${ }^{\mathrm{I}}$ Faculdade do Sul (FACSUL, UNIME). ItABuna/BA - BRAsiL.
Resumo O Brasil se destaca entre os países produtores e consumidores de carne suína, que é destinada ao consumo in natura e também à fabricação de embutidos. O presunto é um alimento cozido, com elevado consumo no mundo. O objetivo do trabalho foi analisar as características microbiológicas de presunto fatiado, comercializado no município de Pau Brasil, Bahia. As amostras de presunto fatiado foram coletadas em três supermercados do município, entre os meses de agosto e setembro de 2014. Em cada coleta, realizou-se um esfregaço com swab estéril nas máquinas fatiadoras. Os resultados se mostraram negativos para coliformes termotolerantes Escherichia. coli, contudo verificou-se a presença de micro-organismos aeróbios mesófilos, coliformes totais e enterobactérias com contagens que variaram de $1,3 \times 10$ a $6,3 \times 10^{3} \mathrm{UFC} / \mathrm{g},<3,0$ a $>1100$ $\mathrm{NMP} / \mathrm{g}$ e $<10$ a $6,4 \times 10^{3} \mathrm{UFC} / \mathrm{g}$, respectivamente. Constatou-se que as máquinas fatiadoras foram as prováveis fontes de contaminação do presunto por enterobactérias. Os resultados sugerem a presença de controle sanitário, evidenciando que as condições higiênicas durante o fatiamento, operações de limpeza e condições de armazenamento seguem um padrão de qualidade de acordo com a legislação vigente.

Palavras-chave: Escherichia coli. Microbiologia de alimenTOS. Higiene dos ALIMENTOS

Abstract Brazil stands out among the pork-producing and consuming countries, which is destined to the in natura consumption and also to the manufacture of sausages. Ham is a cooked food with high consumption worldwide. The objective of this work was to analyze the microbiological characteristics of the sliced ham commercialized in the city of Pau Brazil, Bahia. The samples of sliced ham were collected in three supermarkets of the municipality, between August and September 2014. For each sampling, a smear with sterile swab on the slicing machines was performed. The results were negative for thermotolerant coliforms and E. coli, but the presence of aerobic mesophilic microorganisms, total coliform and enterobacteria with counts ranging from $1.3 \times 10$ to $6.3 \times 10^{3} \mathrm{CFU} / \mathrm{g},<3.0 \mathrm{a}>1100 \mathrm{MPN} / \mathrm{g}$ and $<10$ at $6.4 \times 10^{3} \mathrm{CFU} / \mathrm{g}$ was observed, respectively. It was found that slicing machines were the probable source of contamination of ham by enterobacteria. The results suggest the presence of sanitary control, showing that hygienic conditions during slicing, cleaning operations and storage conditions follow a quality standard according to the current legislation.

KeYWORDS: ESCHERICHIA COLI. FOOD MICROBIOLOGY. FOOD HYGIENE. 


\section{INTRODUÇÃO}

O presunto é um produto cárneo industrializado, obtido dos cortes de membros posteriores de suínos e outras espécies de animais de açougue, desossados ou não, e submetidos a um processo térmico adequado, constituindo-se como um alimento cozido de boa qualidade conservacional, porém suscetível à contaminação cruzada. ${ }^{1,2}$

$\mathrm{O}$ armazenamento do presunto é de fundamental importância para manter a qualidade nutricional do produto e evitar sua contaminação por micro-organismos que podem provocar intoxicações e toxinfecções no ser humano, podendo ter caráter letal. ${ }^{3}$

Alimentos como o presunto fatiado apresentam facilidade para multiplicação microbiana em decorrência de manipulação e armazenamento inadequados. Durante o processo de fatiamento, o presunto fica exposto à proliferação de micro-organismos aeróbios mesófilos, devido ao maior contato com o oxigênio, que pode alterar as características intrínsecas do alimento. Esse processo determina a qualidade do presunto devido às condições de higienização dos equipamentos, e representa importante fonte de contaminação por micro-organismos deteriorantes. ${ }^{4,5}$

Os micro-organismos indicadores, quando presentes em um alimento, são capazes de fornecer informações sobre a ocorrência de contaminação fecal, presença de patógenos ou deterioração potencial do alimento, e também podem mostrar condições higiênico-sanitárias inadequadas durante o processamento, produção ou armazenamento. ${ }^{6}$

A presença de coliformes totais determina as condições de higiene do seu manuseio e dispensa. Contagens elevadas representam contaminação no pós-processamento, limpeza, sanificação deficiente, tratamentos térmicos ineficazes, multiplicação no ato do processamento ou estocagem. A presença de coliformes termotolerantes, em especial a Escherichia coli, evidencia condições higiênico-sanitárias inadequadas e indica a presença de micro-organismos enteropatogênicos nos ambientes e nos produtos alimentícios. ${ }^{\text {? }}$

Considerando que em cidades de pequeno porte a vigilância sanitária não dispõe de condições necessárias para a fiscalização e análises de produtos industrializados com posterior manipulação, como também a falta de conhecimento dos manipuladores sobre boas práticas de manipulação, ${ }^{8}$ fez-se necessário o estudo da qualidade microbiológica de presunto fatiado que é base de diversos pratos culinários no sul da Bahia.

\section{MATERIAIS E MÉtodos}

\section{Delimitação e universo da amostra}

As amostras de presunto fatiado foram coletadas em três supermercados do município de Pau Brasil (estabelecimentos A, B e C), entre os meses de agosto e setembro de 2014. Para cada supermercado, foram coletadas três amostras de 200 gramas, em sacos estéreis, sendo uma amostra por semana com diluição seriada, totalizando nove amostras. No momento da análise, as amostras eram cortadas em pedaços menores com instrumental estéril e homogeneizadas para a retirada da unidade analítica.

A cada coleta, realizou-se um esfregaço com swab estéril nas máquinas fatiadoras, de 
forma que se obtiveram outras nove amostras no total, com a inoculação sendo feita em triplicata. Para a amostragem, retirou-se o swab do meio de transporte STUART (Copan), segurando-se a haste na extremidade oposta à do algodão. Umedeceu-se o algodão no diluente (água peptonada a 0,1\%), comprimindo-o contra as paredes do frasco para remover o excesso de líquido. Delimitou-se a área a ser amostrada na lâmina de corte da máquina fatiadora e deslizou-se o swab com pressão, realizando movimentos da esquerda para a direita e de baixo para cima, girando o swab continuamente, para que toda a superfície do algodão entrasse em contato com a lâmina de corte. Reintroduziu-se o swab novamente no meio de transporte.

As amostras de presunto fatiado e os esfregaços de superfície foram acondicionados em caixas térmicas, com gelo, e encaminhados para o Laboratório de Pesquisa Clínica I, localizado na Faculdade do Sul - FACSUL, UNIME, Itabuna, Bahia, para a realização das análises microbiológicas.

\section{Avaliação microbiológica}

Para a realização das análises microbiológicas, tomou-se a unidade analítica de $10 \mathrm{~g}$ de cada amostra de presunto fatiado, seguida da realização de diluições seriadas em água peptonada a $0,1 \%\left(1^{\mathrm{a}}, 2^{\mathrm{a}}\right.$ e $3^{\mathrm{a}}$ diluições), segundo recomendações encontradas em bibliografia especializada. ${ }^{9}$ As variáveis analisadas foram: contagem total de micro-organismos aeróbios mesófilos, contagem de enterobactérias, contagem de coliformes totais, coliformes termotolerantes e Escherichia coli. Os swabs das máquinas fatiadoras foram analisados para a contagem de enterobactérias.

\section{Contagem total de micro-orga- nismos aeróbios mesófilos}

Empregou-se o meio Ágar Padrão para Contagem - PCA (Merck), utilizando-se o método de plaqueamento em profundidade. ${ }^{9}$ Inoculou-se $1 \mathrm{~mL}$ das diluições das amostras previamente preparadas em placas de Petri estéreis e vazias. Após resfriamento $\left(44-46^{\circ} \mathrm{C}\right)$, o PCA foi vertido (12 a $15 \mathrm{~mL}$ ) nas placas de Petri contendo a amostra e, por meio de movimentos circulares suaves em forma de " 8 ", misturou-se o inóculo com o meio de cultura. Com a solidificação do meio, as placas foram invertidas e incubadas em estufa regulada a $35 \pm 1^{\circ} \mathrm{C}$ por 48 horas.

Para contagem das colônias, selecionaram-se as placas com 25 a 250 colônias e, para calcular o número de unidades formadoras de colônias (UFC) por grama de presunto fatiado, multiplicou-se o número de colônias pelo inverso da diluição inoculada.

\section{Contagem de Enterobactérias}

Empregou-se o meio Ágar Vermelho Violeta Bile Dextrose - VRBD (Merck), utilizando-se o método de plaqueamento em profundidade com sobrecamada. ${ }^{9}$ Inoculou-se $1 \mathrm{~mL}$ das diluições das amostras previamente preparadas em placas de Petri estéreis e vazias.

Já os swabs foram transferidos para tubos de ensaio contendo $10 \mathrm{~mL}$ de água peptonada a $0,1 \%$. Com o auxílio de uma tesoura esterilizada, cortou-se a haste manuseada para que somente a extremidade do algodão tivesse contato com o diluente. Após agitação dos swabs em movimentos circulares, retirou-se alíquotas de $1 \mathrm{~mL}$, em triplicatas, para placas de Petri estéreis e vazias. 
Após resfriamento $\left(44-46^{\circ} \mathrm{C}\right)$, o VRBD foi vertido (12 a $15 \mathrm{~mL}$ ) nas placas de Petri e, por meio de movimentos circulares suaves em forma de " 8 ", misturou-se o inóculo com o meio de cultura. Com a solidificação do meio, cobriu-se as placas com uma sobrecamada $(5-8 \mathrm{~mL})$ do mesmo meio, as quais foram incubadas em posição invertida em estufa regulada a $35 \pm 1^{\circ} \mathrm{C}$ por 24 horas.

Para a contagem das colônias, selecionaram-se as placas com 15 a 150 colônias com coloração vermelho púrpura, rodeadas por um halo avermelhado no meio seletivo VRBD. O número de UFC por grama de presunto fatiado foi calculado multiplicando-se o número de colônias pelo inverso da diluição inoculada. Já o número de UFC por swab foi obtido por intermédio da média da contagem de UFC nas três placas inoculadas.

\section{Contagem de Coliformes totais, Coliformes termotolerantes e Escherichia coli}

Para o teste presuntivo, empregou-se o caldo Lauril Sulfato Triptose - LST (Merck); para a confirmação de coliformes totais, utilizou-se o caldo Verde Brilhante Bile 2\% - VB (Merck) e, para a confirmação de coliformes termotolerantes, usou-se o caldo $E$. coli - EC (Merck), empregando-se o método do Número Mais Provável - NMP. ${ }^{9}$
Inoculou-se $1 \mathrm{~mL}$ das diluições das amostras previamente preparadas em uma série de três tubos contendo LST e tubos de Durhan invertidos. Após a inoculação, procedeu-se com a incubação dos tubos em estufa regulada a $35 \pm 1^{\circ} \mathrm{C}$ por 48 horas. O LST possui lactose e a observação do crescimento microbiano, por intermédio da turvação do meio com a produção de gás decorrente da fermentação, procedendo-se à confirmação para coliformes totais e termotolerantes. A partir dos tubos com LST positivos, transferiu-se uma alçada da cultura, com uma alça calibrada, para os tubos com VB e com EC, ambos com tubos de Durhan invertidos. A incubação foi feita em estufa regulada a $35 \pm 1^{\circ} \mathrm{C}$ por 48 horas e em banho maria regulado a $45,5^{\circ} \mathrm{C}$ por 24 horas, respectivamente. Após o período de incubação, verificou-se se houve crescimento com presença de gás nos tubos de Durhan. Para a determinação dos valores de coliformes totais e termotolerantes nas amostras de presunto fatiado, utilizou-se a tabela de NMP.

\section{RESUlTAdos E Discussões}

Os resultados obtidos após as análises microbiológicas das nove amostras de presuntos fatiados estão demonstrados nas Tabelas 1, 2 e 3 para cada estabelecimento comercial amostrado.

Tabela 1: Resultados microbiológicos do presunto fatiado - Estabelecimento A.

\begin{tabular}{|c|c|c|c|c|c|}
\hline & $\begin{array}{l}\text { Aeróbios mesófilos } \\
\text { (UFC/g) }\end{array}$ & $\begin{array}{l}\text { Enterobactérias } \\
\text { (UFC/g) }\end{array}$ & Coliformes totais (NMP/g) & $\begin{array}{l}\text { Coliformes termotolerantes } \\
(\mathrm{NMP} / \mathrm{g})\end{array}$ & E. coli \\
\hline Amostra 1 & $5,0 \times 10^{3}$ & $2,2 \times 10^{3}$ & $>1.100$ & $<3,0$ & AUS \\
\hline Amostra 2 & $7,0 \times 10^{2}$ & $1,3 \times 10^{3}$ & $>1.100$ & $<3,0$ & AUS \\
\hline Amostra 3 & $6,3 \times 10^{3}$ & $5,1 \times 10^{2}$ & $<3,0$ & $<3,0$ & AUS \\
\hline
\end{tabular}

AUS = Ausente; NMP/g = Número Mais Provável por grama; UFC/g= Unidade formadora de colônia por grama. 
Tabela 2: Resultados microbiológicos do presunto fatiado - Estabelecimento B.

\begin{tabular}{c|c|c|c|c|c}
\hline & $\begin{array}{c}\text { Aeróbios } \\
\text { mesófilos } \\
(\mathrm{UFC} / \mathrm{g})\end{array}$ & $\begin{array}{c}\text { Enterobactérias } \\
\text { (UFC/g) }\end{array}$ & Coliformes totais (NMP/g) & $\begin{array}{c}\text { Coliformes } \\
\text { termotolerantes } \\
(\mathrm{NMP} / \mathrm{g})\end{array}$ \\
\hline Amostra 1 & $>10^{3}$ & $1,2 \times 10^{3}$ & $>1.100$ & $<3,0$ & AUS \\
\hline Amostra 2 & $3,7 \times 10^{2}$ & $6,4 \times 10^{3}$ & $>1.100$ & $<3,0$ & AUS \\
\hline Amostra 3 & $1,2 \times 10^{3}$ & 10 & $>1.100$ & $<3,0$ & AUS \\
\hline
\end{tabular}

AUS = Ausente; $\mathrm{NMP} / \mathrm{g}=$ Número Mais Provável por grama; UFC/g= Unidade formadora de colônia por grama.

Tabela 3: Resultados microbiológicos do presunto fatiado - Estabelecimento C.

\begin{tabular}{|c|c|c|c|c|c|}
\hline & $\begin{array}{l}\text { Aeróbios } \\
\text { mesófilos } \\
\text { (UFC/g) }\end{array}$ & Enterobactérias (UFC/g) & Coliformes totais (NMP/g) & $\begin{array}{c}\text { Coliformes } \\
\text { termotolerantes } \\
(\mathrm{NMP} / \mathrm{g})\end{array}$ & E. coli \\
\hline Amostra 1 & $1,3 \times 10^{3}$ & $<10$ & $<3,0$ & $<3,0$ & AUS \\
\hline Amostra 2 & $2,9 \times 10^{3}$ & $<10$ & 7,4 & $<3,0$ & AUS \\
\hline Amostra 3 & $1,3 \times 10$ & $<10$ & $>1.100$ & $<3,0$ & AUS \\
\hline
\end{tabular}

AUS = Ausente; NMP/g = Número Mais Provável por grama; UFC/g= Unidade formadora de colônia por grama.

A contagem total de micro-organismos aeróbios mesófilos apresentou valores compreendidos nos intervalos de $7 \times 10^{2}$ a $6,3 \times 10^{3} \mathrm{UFC} / \mathrm{g}$ para o estabelecimento $\mathrm{A}$, $3,7 \times 10^{2}$ a $>10^{3} \mathrm{UFC} / \mathrm{g}$ para o estabeleci-

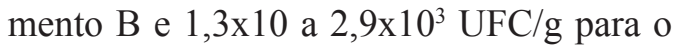
estabelecimento $\mathrm{C}$. Na norma brasileira da ANVISA, ${ }^{10}$ a qual define padrões microbiológicos para o presunto, não há limites específicos para a contagem total de micro-organismos aeróbios mesófilos. ${ }^{11}$

A maioria dos alimentos apresenta alterações detectáveis quando possuem números de aeróbios mesófilos superiores a $10^{6} \mathrm{UFC} / \mathrm{g}$ do alimento. ${ }^{11}$ Numa pesquisa realizada em Francisco Beltrão, Paraná, na qual se analisaram 14 amostras de presunto fatiado, foram encontrados valores compreendidos entre $2,5 \times 10$ a 2,6 x $10^{4} \mathrm{UFC} / \mathrm{g}$ para os micro-organismos aeróbios mesófilos, ${ }^{6}$ resultados comparáveis aos encontra- dos no presente estudo. Contagens superiores $\left(10^{5}\right.$ a $\left.10^{8} \mathrm{UFC} / \mathrm{g}\right)$ foram observadas em Fortaleza, Ceará, após a análise de 10 amostras de presunto fatiado. ${ }^{5}$

$\mathrm{Na}$ contagem de enterobactérias, foram encontrados resultados que variaram de $5,1 \times 10^{2}$ a $2,2 \times 10^{3} \mathrm{UFC} / \mathrm{g}$ para o estabelecimento A, 10 a $6,4 \times 10^{3} \mathrm{UFC} / g$ para o estabelecimento $\mathrm{B}$ e $<10 \mathrm{UFC} / \mathrm{g}$ para o estabelecimento C. A pesquisa dessas bactérias indica as condições de higiene das máquinas fatiadoras, bem como, da manipulação do produto, portanto o estabelecimento $\mathrm{C}$ demonstrou seguir as boas práticas de higiene.

A presença desses micro-organismos mostra deficiência de higienização do manipulador do alimento, como também no seu fatiamento, pois as enterobactérias são facilmente inativadas pelos sanitizantes. $\mathrm{Na}$ norma brasileira da ANVISA, ${ }^{10}$ a qual define padrões microbiológicos para o presun- 
to, não há limites específicos para a contagem total de enterobactérias. ${ }^{12}$

Em pesquisa realizada no município de São Luís, Maranhão, foram analisadas três amostras de presuntos conservados em embalagens plásticas seladas, onde se observou o crescimento de bactérias patogênicas pertencentes aos gêneros Salmonella, Enterobacter, Shigella e Staphylococcus em uma das amostras. ${ }^{13}$ Resultado semelhante ao dessa pesquisa, quanto à presença dos gêneros Salmonella e Listeria, foi encontrado em supermercados na cidade de Fortaleza, indicando a necessidade de orientação para o correto acondicionamento, e manuseio desse tipo de alimento. ${ }^{14}$

A contagem de coliformes totais apresentou resultados que variaram de $<3,0 \mathrm{a}>1100$ $\mathrm{NMP} / \mathrm{g}$ para o estabelecimento A e C. Já para o estabelecimento B, as três amostras mostraram valores superiores a $1100 \mathrm{NMP} / \mathrm{g}$ do produto. Na norma brasileira da ANVISA, ${ }^{10}$ que define padrões microbiológicos para o presunto, não há limites específicos para a contagem total de coliformes totais.

Na cidade de Pombal, Paraíba, um estudo envolvendo a análise microbiológica de seis amostras de presunto fatiado constatou resultados positivos para a presença de coliformes totais em quatro amostras analisadas, cujos valores variaram de 7 a $15 \mathrm{NMP} / \mathrm{g} \cdot{ }^{15} \mathrm{O}$ acondicionamento adequado e o uso correto das embalagens podem prevenir esse tipo de contaminação. ${ }^{7}$ Mesmo no Distrito Federal, onde a fiscalização é mais presente, valores elevados de coliformes totais foram encontrados. ${ }^{16}$ Esse fato demonstra que, além de uma boa higiene do ambiente de manuseio do presunto, outros fatores como a temperatura do ambiente, ou até a forma como é transportado até o ponto de venda, podem levar ao quadro de contaminação. ${ }^{17}$

Os resultados para coliformes termotolerantes e $E$. coli se mostraram negativos para as amostras analisadas, estando todas em conformidade com o preconizado pela RDC No. 12 de janeiro de 2001, da Agência Nacional de Vigilância Sanitária (ANVISA).${ }^{10}$ De acordo com a resolução, o padrão microbiológico de coliformes a $45^{\circ} \mathrm{C} / \mathrm{g}$ de presunto fatiado é até $10^{3} \mathrm{NMP} / \mathrm{g}$ para a amostra indicativa.

Os resultados obtidos no presente estudo demonstram que as áreas utilizadas para o fatiamento de presunto não mostravam contaminação de origem fecal, uma vez que esses micro-organismos (i.e., coliformes termotolerantes e E. coli) possuem como principal habitat o trato intestinal de animais. ${ }^{11,13}$ A presença desses grupos indicaria o contato direto ou indireto com material de excretas dos manuseadores do alimento, ou de outros animais, que por ali poderiam transitar.

No entanto, essa constatação não se aplica facilmente a qualquer ambiente. Em pesquisa realizada em São Luís, Maranhão, foram analisadas 30 amostras de presunto fatiado para a presença de coliformes a $45^{\circ} \mathrm{C}$, sendo que sete amostras apresentaram contaminação, com valores compreendidos $\mathrm{de}<3,0$ a $1100 \mathrm{NMP} / \mathrm{g} .{ }^{13}$

A manutenção das condições básicas de higiene, a orientação e o treinamento adequados no trato com esse tipo de alimento evitam a contaminação pelos coliformes termotolerantes e E. coli, as quais não devem representar qualquer tipo de dificuldade para os estabelecimentos e/ou funcionários. ${ }^{18,19}$

Os resultados obtidos após a contagem de enterobactérias nas nove amostras de esfregaços das máquinas fatiadoras estão demonstrados na Tabela 4. 
Tabela 4: Resultados das contagens de enterobactérias nas amostras coletadas das superfícies das lâminas de corte das máquinas fatiadoras em três diferentes estabelecimentos comerciais.

\begin{tabular}{c|c|c}
\hline Estabelecimento & Amostra & Enterobactérias (UFC/swab) \\
\hline \multirow{4}{*}{ A } & 1 & 38 \\
\cline { 2 - 3 } & 2 & 27 \\
\cline { 2 - 3 } & 3 & 22 \\
\hline \multirow{4}{*}{ B } & 1 & INC \\
\cline { 2 - 3 } & 2 & 200 \\
\cline { 2 - 3 } & 3 & 36 \\
\hline \multirow{3}{*}{ C } & 1 & 0 \\
\cline { 2 - 3 } & 2 & 0 \\
\cline { 2 - 3 } & 3 & 0 \\
\hline
\end{tabular}

INC = Incontáveis; UFC/swab= Unidade formadora de colônia por swab.

Os resultados obtidos demonstraram a presença de enterobactérias em seis amostras de swabs da superfície das máquinas fatiadoras. A contagem de enterobactérias em uma das amostras coletadas na superfície da máquina fatiadora do estabelecimento B não pôde ser determinada por exibir incontáveis colônias. No estabelecimento A, a maior contagem verificada foi de $38 \mathrm{UFC/}$ swab, enquanto que no estabelecimento $\mathrm{C}$ não houve detecção de enterobactérias na superfície da máquina fatiadora.

Durante o trabalho, verificou-se ausência de enterobactérias tanto na máquina fatiadora, como também no presunto fatiado do estabelecimento C. Nos estabelecimentos A e B, a presença de enterobactérias provavelmente decorreu da não higienização ou higienização incorreta das máquinas fatiadoras, como também por meio de contaminação cruzada com o manipulador. ${ }^{20}$ Além disso, observou-se que o número de enterobactérias diminuiu, principalmente no estabelecimento B, com o passar das semanas, indicando maior cuidado dos manipuladores em relação às medidas de higiene por conta da pesquisa.

A higienização incorreta de equipamentos e áreas onde ocorrem a produção, manipulação e comercialização de alimentos aumenta a probabilidade de contaminação microbiana, inclusive por micro-organismos patogênicos, e proporciona a diminuição no tempo de prateleira. ${ }^{21} \mathrm{Em}$ muitos alimentos, principalmente os industrializados como o presunto, a higienização do ambiente onde acontece a manipulação, a estocagem é um fator decisivo na segurança do alimento, e a utilização de métodos para detectar micro-organismos indicadores de contaminação é uma alternativa para a verificação da eficiência das técnicas de higienização. ${ }^{22}$ 


\section{CONSIDERAÇões FINAIS}

A presença de micro-organismos aeróbios mesófilos foi identificada em todas as amostras de presunto fatiado analisadas.

Enterobactérias e coliformes totais foram identificados em grande parte das amostras (66,7\%), mostrando carência de boas práticas de manipulação e conservação durante as etapas de fracionamento e acondicionamento do presunto. Esses micro-organismos foram também encontrados nas amostras dos swabs coletados nas superfícies das máquinas fatiadoras nos estabelecimentos A e B. Contudo, no estabelecimento $C$ não houve detecção de enterobactérias, mostrando que esse estabelecimento mantinha as boas práticas de higiene, atendendo ao disposto na Resolução RDC no. 216, de 15 de setembro de 2004 que dispõe sobre Regulamento Técnico de Boas Práticas para Serviços de Alimentação.

Por sua vez, constatou-se a ausência de coliformes termotolerantes e E. coli, indicando que os ambientes apresentavam cuidados básicos com limpeza e acomodação dos produtos. As nove amostras de presunto fatiado analisadas para coliformes termotolerantes estavam em condições sanitárias satisfatórias, e o alimento próprio para o consumo, conforme o padrão microbiológico estabelecido pela ANVISA.

\section{REFERÊNCIAS}

1. Aaslyng MD, Vestergaard C., Koch AG. The effect of salt reduction on sensory quality and microbial growth in hotdog sausages, bacon, ham and salami. Meat Sci. 2014; 96 (1): 47-55.

2. dos Santos CCP, Mattanna P. Controle de Qualidade Físico-Químico de Marcas Comerciais de Presunto Cozido Fatiado. Rev. Elet. Bioc. Biotec. e saúde. 2016; 8 (17): 10-10.

3. JAY, M. Microbiologia dos alimentos, 6. ed. Porto Alegre: Artmed; 2005.

4. Bressan MC, Lodi F., Ferreira MW, Andrade PL, Boari, CA, Piccoli RH. Influência da embalagem na vida útil de presuntos fatiados. Ciênc. Agrotec. 2007; 31 (2): 433-438.

5. Serio J., Muniz CR, Freitas CAS, Lima JR, Souza Neto JA. Avaliação microbiológica e microscópica de presuntos fatiados refrigerados. Alim. Nutr. 2009; 20 (1): 135-139.

6. Fachinello J., Casaril K. Avaliação da qualidade microbiológica de presuntos fatiados, comercializados no município de Francisco Beltrão, Paraná. Braz. J. Food Nutr. 2013; 24 (3): 333-337.

7. Kim JH, Lee HR, Pyun CW, Kim SK, Lee CH. Changes in Physicochemical, Microbiological and Sensory Properties of Dry Cured Ham in Processed Sulfur Fed Pigs. J. of Food Proc. and Preserv. 2015; 39 (6): 829-839.

8. da Silva Silvestre MK, Abrantes MR, Paiva WS, Souza ÊS, Silva JBA. Avaliação da qualidade da carne bovina in natura comercializada no município de Alexandria-RN. Acta vet. Brasílica. 2013; 7 (4): 327-331.

9. Silva N. Manual de métodos de análise microbiológica de alimentos e água, 4. ed. São Paulo: Varela; 2010.

10. Brasil. Ministério da Saúde. Agência Nacional de Vigilância Sanitária. Resolução n. 12, de 2 janeiro de 2001. Regulamento técnico sobre padrões microbiológicos para alimentos. Diário Oficial da República Federativa do Brasil, Brasília, 10 jan. 2001, n. 7-E, Seção 1.

11. Franco B., Landgraf M. Microbiologia dos alimentos. São Paulo: Atheneu, 2008.

12. Terra NN, Cichoski AJ, de Freitas RJS. Aspectos microbiológicos e físico-químicos da parte interna da paleta suína curada, maturada e fermentada durante a etapa de processamento e armazenamento. Ciênc. Rural. 2008; 38 (4): 1.118-1.125. 
13. Menezes PMS, Coelho LM, Costa FN. Avaliação da qualidade higiênico-sanitária dos presuntos fatiados comercializados na cidade de São Luís, MA. Biológico. 2010; 72 (1): 11-17.

14. Fai AEC, Figueiredo EATD, Verdin SEF, Pinheiro NMDS, Braga ARC, Stamford TLM. Salmonella sp. e Listeria monocytogenes em presunto suíno comercializado em supermercados de Fortaleza (CE, Brasil): fator de risco para a saúde pública. Ciênc. \& Saúde Col. 2011; 16: 657-662.

15. Barreto, E., Kaminski S. Coliformes totais e termotolerantes de presunto fatiado comercializado em supermercados do município de Sorriso-Mato Grosso, Brasil. REBES. 2013; 3 (3): 59-63.

16. Fonseca JG, Pereira MG. Bacterial contamination of sandwiches sold in snack bars: cross-sectional study carried out in Brasilia, Brazil. Epidemiologia e Serviços de Saúde. 2013; 22 (3): 509-516.

17. Andrade NJ. Higiene na Indústria de Alimentos: avaliação e controle da adesão e formação de biofilmes bacterianos. São Paulo: Varela, 2008.

18. Rossi P., Bampi GB. Qualidade microbiológica de produtos de origem animal produzidos e comercializados no Oeste Catarinense. Segur. Alim. e Nut. 2015; 22 (2): 748-757.

19. da Silva Campêlo MC, de Medeiros JMS, Pinto MMF, de Assis APP, da Silva JBA, de Oliveira Lima P. Perfil sanitário e características físico-químicas da carne ovina comercializada in natura. Rev. do Inst. Adolfo Lutz. 2015; 74 (3): 207-215.

20. Chen D., Zhao T., Doyle MP). Transfer of foodborne pathogens during mechanical slicing and their inactivation by levulinic acid-based sanitizer on slicers. Food microb. 2014; 38: 263-269.

21. Martins RB, Hogg T, Otero JG. Food handlers' knowledge on food hygiene: The case of a catering company in Portugal. Food Control. 2012; 23 (1): 184-190.

22. Araújo EA, Pires ACS, Camilloto GP, Ribeiro MCT, Soares NFF, Andrade NJ. Condições Higiênicas de fatiadores de frios avaliadas por ATP - bioluminescência e contagem microbiana. Hig. Aliment. 2007; 21 (150): 114-115.

\section{DAdOS DOS AUTORES}

Adenilson Soares Sena

Graduado em Farmácia. Faculdade do Sul (FACSUL, UNIME). Itabuna/BA - Brasil. othoncandi@, hotmail.com

\section{Marcel Vieira Santana}

Graduado em Farmácia. Faculdade do Sul (FACSUL, UNIME), Itabuna/BA - Brasil. mvsantana2009@hotmail.com

\section{Gedeany Alves Nascimento}

Graduanda em Farmácia. Faculdade do Sul (FACSUL, UNIME). Itabuna/BA - Brasil. gedeany_alves@hotmail.com

\section{Marcio Amorim Tolentino Lima}

Mestre em Sistemas Aquáticos Tropicais pela Universidade Estadual de Santa Cruz (UESC). Docente do Curso de Farmácia Faculdade do Sul (FACSUL, UNIME). Itabuna/BA - Brasil. marcioatl@ yahoo.com.br

\section{Lucas Ribeiro Carvalho}

Mestre em Biologia e Biotecnologia de Microrganismos pela Universidade Estadual de Santa Cruz (UESC). Docente da Faculdade do Sul (FACSUL, UNIME). Itabuna/BA - Brasil. lucas_carv@hotmail.com

Submetido em: 27-11-2018

Aceito em: 3-10-2019 